\title{
PRE-PLACED VERSUS POST-PLACED CORNEO-SCLERAL SUTURES IN CATARACT SURGERY*
}

\author{
BY \\ DHANWANT SINGH \\ Department of Ophthalmology, Government Medical College, Patiala, Punjab, India
}

THE closure and healing of the wound in cataract surgery is a most important factor in the success of the operation, and various suturing techniques have been evolved.

The present communication attempts to evaluate the results in 668 cases operated on from January to November, 1961. The same pre-operative preparation, operative technique, and post-operative treatment were used, and the same thread $(16 \times 0$ black silk $\dagger)$ was used for the corneo-scleral sutures, which were applied under a limbal-based conjunctival flap. These 668 cases may be divided into two groups, according to the placing of the sutures. In 313 cases three post-placed corneo-scleral sutures were used, and in the other 355 cases the three corneo-scleral sutures were pre-placed in a gutter formed at the limbus.

\section{Operative Steps}

Group I.-A limbal-based conjunctival flap was made, an ab externo limbal incision being made at 12 o'clock with a razor blade held in the tip of a needle-holder (Fig. 1).

The limbal incision was enlarged with corneal scissors, and three postplaced corneo-scleral sutures were applied at 11,12 , and 1 o'clock before the delivery of the lens (Fig. 2).

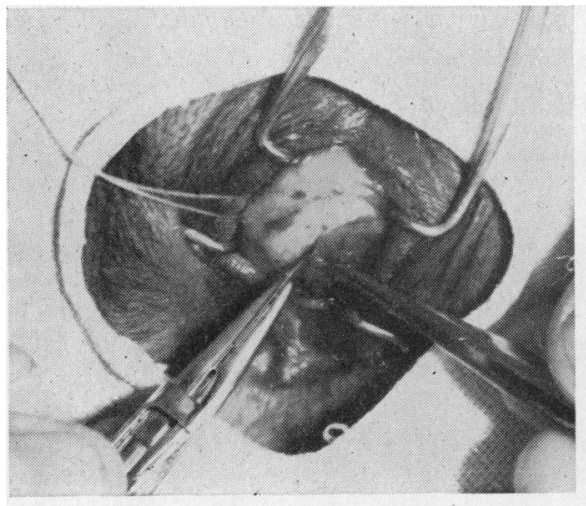

Fig. 1.- Ab externo limbal incision at 12 o'clock with a razor blade held in the tip of a needle-holder.

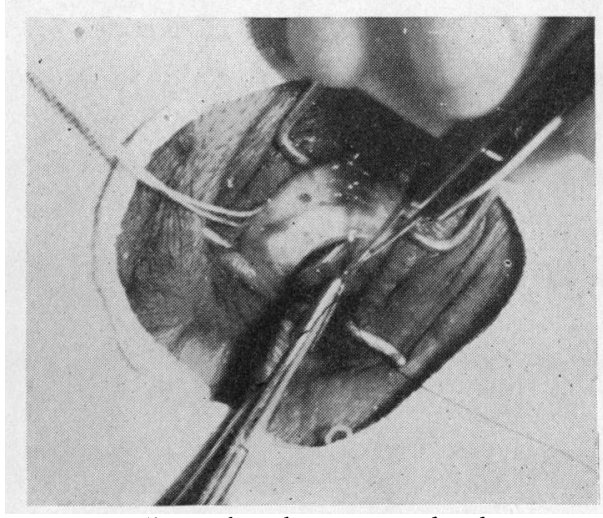

Fig. 2.-Post-placed corneo-scleral sutures being passed through the lips of the wound.

* Received for publication March 9, 1962.

+ The $16 \times 0$ silk was prepared by dividing $4 \times 0$ silk into four parts. 
Group II.-A gutter was made to three-quarters of the depth of the tissue from 2 to 10 o'clock at the limbus under the limbal-based conjunctival flap (Fig. 3). Three corneo-scleral sutures were applied at 11, 12, and 1 o'clock through the lips of the gutter (Fig. 4), the needle being passed through half the thickness of the tissue. The loops of the sutures were pulled out (Fig. 5 ), the incision at 12 o'clock was deepened until the blade entered the anterior chamber, and the wound was enlarged to the required size with corneal scissors (Fig. 6).

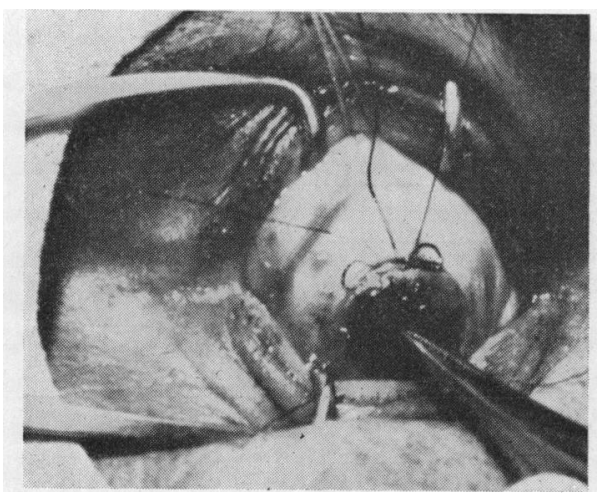

Fig. 3.-Gutter formed at the limbus from 2 to 10 o'clock.

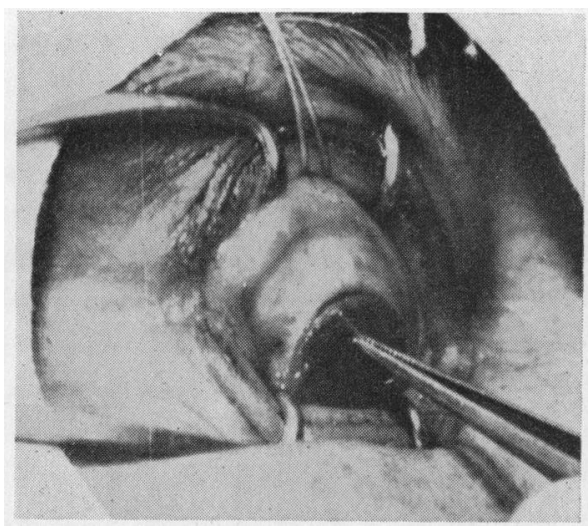

Fig. 5.-Suture loops pulled out before opening the anterior chamber.

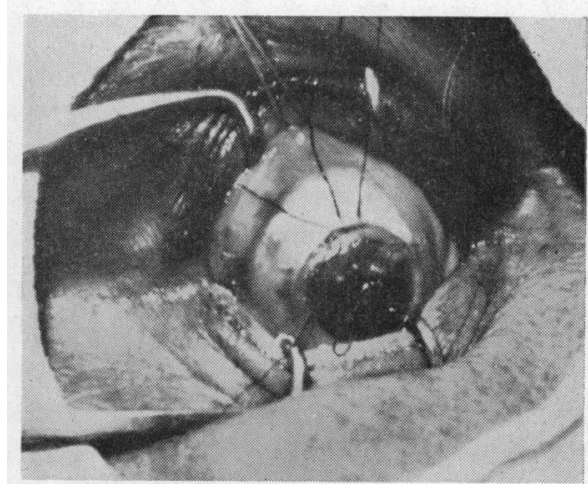

Fig. 4.-Three pre-placed sutures passed through the lips of the gutter.

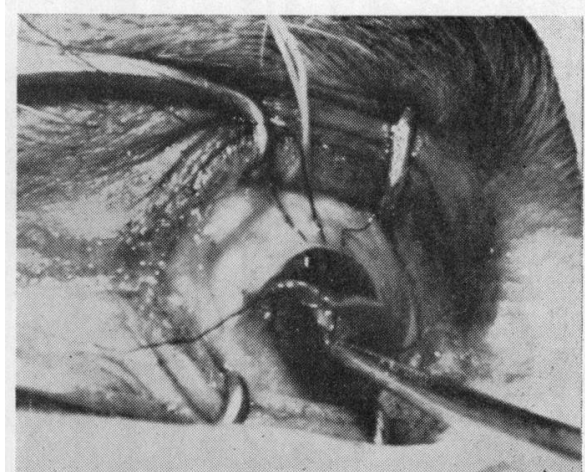

Fig. 6.-Anterior chamber opened and section enlarged to required size.

In both groups intracapsular extraction with Arruga's forceps was planned, unless contraindicated, and air was injected at the end of the operation to deepen the anterior chamber. 


\section{Post-operative Complications}

Both groups showed examples of shallow anterior chamber, hyphaema, and iris prolapse. The analysis given in Table I and Fig. 7 shows that in Group II, in which pre-placed sutures were used, the complications of shallow anterior chamber and hyphaema were only about 60 per cent. as frequent as in Group I, and that the incidence of iris prolapse was reduced to about 20 per cent. of that in Group I.

TABLE I

POST-OPERATIVE COMPLICATIONS

\begin{tabular}{|c|c|c|c|c|c|c|c|c|}
\hline \multirow{3}{*}{ Group } & \multirow{3}{*}{ Corneo-scleral Sutures } & \multirow{3}{*}{$\begin{array}{l}\text { Total } \\
\text { No. of } \\
\text { Cases }\end{array}$} & \multicolumn{6}{|c|}{ Complications } \\
\hline & & & \multicolumn{2}{|c|}{$\begin{array}{l}\text { Shallow } \\
\text { Anterior } \\
\text { Chamber }\end{array}$} & \multicolumn{2}{|c|}{ Hyphaema } & \multicolumn{2}{|c|}{$\begin{array}{c}\text { Iris } \\
\text { Prolapse }\end{array}$} \\
\hline & & & No. & Per cent. & No. & Per cent. & No. & Per cent. \\
\hline II & $\begin{array}{l}\text { Post-placed } \\
\text { Pre-placed }\end{array}$ & $\begin{array}{l}313 \\
355\end{array}$ & $\begin{array}{l}50 \\
31\end{array}$ & $\begin{array}{r}16 \\
9\end{array}$ & $\begin{array}{l}31 \\
20\end{array}$ & $\begin{array}{r}10 \\
6\end{array}$ & $\begin{array}{l}9 \\
2\end{array}$ & $\begin{array}{c}3 \\
0.5\end{array}$ \\
\hline \multicolumn{2}{|l|}{ Total } & 668 & 81 & - & 51 & - & 11 & - \\
\hline
\end{tabular}

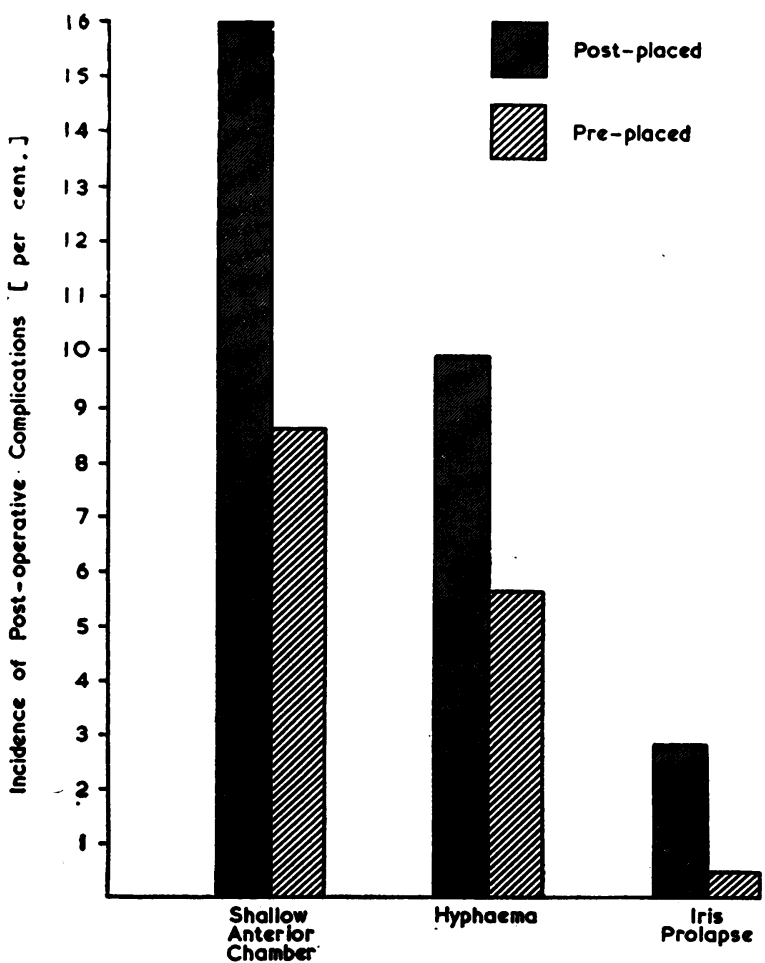

FIG. 7.-Incidence of post-operative complications with post-placed and pre-placed sutures. 
Shallow Anterior Chamber.-A further analysis is given in Table II.

In Group II 81 per cent. of cases of shallow anterior chamber spontaneously returned to normal within 24 hours compared with only 48 per cent. in Group I. In Group II only 13 per cent. remained shallow for more than 48 hours compared with 36 per cent. in Group I. Further surgery was required in only 3 per cent. of cases in Group II compared with 8 per cent. in Group I.

TABLE II

SHALLOW ANTERIOR CHAMBER

\begin{tabular}{l|c|c|c|c|c}
\hline \multicolumn{2}{l|}{} & \multicolumn{2}{|c|}{ I } & \multicolumn{2}{|c}{ II } \\
\hline \multirow{2}{*}{ Corneo-scleral Sutures } & & \multicolumn{2}{|c}{ Post-placed } & \multicolumn{2}{|c}{ Pre-placed } \\
\hline & No. & Per cent. & No. & Per cent. \\
\hline Duration of Shallow Anterior & 24 & 24 & 48 & 25 & 81 \\
Chamber (hrs) & 48 & 8 & 16 & 2 & 6 \\
& $48+$ & 18 & 36 & 3 & 13 \\
\cline { 2 - 6 } & Total & 50 & - & 31 & - \\
\hline Surgery required & & 4 & 8 & 1 & 3 \\
\hline
\end{tabular}

Hyphaema.-A further analysis is given in Table III.

In Group II 60 per cent. showed a streak which disappeared spontaneously within 24 hours, compared with 42 per cent. in Group I, and in Group II only 5 per cent. required further surgery compared with 13 per cent. in Group I.

TABLE III

HYPHAEMA

\begin{tabular}{|c|c|c|c|c|c|}
\hline \multicolumn{2}{|l|}{ Group } & \multicolumn{2}{|c|}{ I } & \multicolumn{2}{|c|}{ II } \\
\hline \multirow{2}{*}{\multicolumn{2}{|c|}{ Corneo-scleral Sutures }} & \multicolumn{2}{|c|}{ Post-placed } & \multicolumn{2}{|c|}{ Pre-placed } \\
\hline & & No. & Per cent. & No. & Per cent. \\
\hline \multirow[t]{2}{*}{ Hyphaema } & Total & 31 & - & 20 & - \\
\hline & Streak disappearing within $24 \mathrm{hrs}$ & 13 & 42 & 12 & 60 \\
\hline \multicolumn{2}{|c|}{ Surgery required } & 4 & 13 & 1 & 5 \\
\hline
\end{tabular}

\section{Discussion}

In general surgery even the smallest incision is surgically closed at the end of the operation, but some ophthalmic surgeons do not use sutures in cataract surgery (14 per cent. in the United Kingdom according to Zorab, 1961). In the author's opinion suturing is essential in cataract extraction, because the patient's vision may depend upon firm and early union of the section. 
Various types of suture are used, the main classification being into preplaced and post-placed.

\section{Pre-placed Sutures}

(a) Without a Previous Gutter (non-penetrating) Incision.-Kalt (1894) introduced two vertically-placed sutures through the cornea and scleral conjunctiva, making two stitches $2-3 \mathrm{~mm}$. apart. After the stitches were passed, the section was made by passing the knife between the two needle holes. Márquez (1913) added a knot to Kalt's sutures to assist quick closure of the wound immediately after the delivery of the lens. Liégard (1913) introduced similar sutures but placed them horizontally, and Stallard (1950) also used horizontally-placed sutures.

These sutures are favoured by some surgeons because they are simple and easy to apply, but they do not give such good apposition as that provided by passing the needle through the lips of a previously-formed gutter.

(b) Through the Lips of a Gutter (non-penetrating) Incision.-Suarez de Mendoza (1891) appears to have been the first to advocate the introduction of sutures through the lips of a non-penetrating incision before completing the section. McLean (1940), after making a conjunctival flap, passed preplaced sutures through the gutter formed with the knife. The sutures passed out of the conjunctiva and were knotted on the surface. Hughes (quoted by Callahan, 1956) used double-mattress sutures in a similar way.

Bodian (1961) uses a fornix-based flap, makes a gutter at the limbus, and passes $6 \times 0$ silk stitches through the lips of the gutter, taking a long stitch of 2-3 mm. into the cornea and sclera. His view is that the long stitches give a wider arc of protection to the section. Escapini (1958) makes a limbal-based conjunctival flap, passes sutures through the gutter, and ties them outside the conjunctiva. Gibson Moore (1958) uses one pre-placed and two post-placed sutures.

Verhoeff (1927) used track sutures. He made an incision in the conjunctiva at the limbus from 9 to 3 o'clock and passed the needle in at the limbus, through the cornea, and out $2 \mathrm{~mm}$. above in the sclera and conjunctiva. The section was made at the limbus with a knife cutting through the threads. After sectioning, new sutures were passed through the same track. This method has the advantage of placing the stitches accurately, but the depth and distance of the sutures from the edges of the wound are not properly controlled. Verhoeff's sutures were modified by Lemoine (1953), who prepared a limbal-based conjunctival flap and then passed track sutures.

\section{Post-placed Sutures}

Some surgeons use these without a flap, and others with a conjunctival flap, either limbal-based or fornix-based. Either silk or cat-gut may be used. Silk sutures are removed after varying intervals. Cat-gut sutures 
may be plain or mildly chromicized (Davis, 1944; Hughes, Guy, and Romaine, 1944; Dunnington and Regan, 1953; Roberts, 1952; Kiffney and Stocker, 1960). Cat-gut sutures may be buried and may cause less irritation, but erosion of the conjunctiva may still occur in some cases.

\section{Present Series}

I have used silk $16 \times 0$ sutures buried under the conjunctival flap. The post-operative reaction has usually been negligible. In some cases the sutures remained buried indefinitely, but in others they eroded the conjunctiva and had to come out after 2 to 3 weeks, when they were picked out by the forceps without any discomfort or local anaesthetic.

The comparison of post-placed and pre-placed sutures under identical conditions has shown that the latter give markedly better results. The meridian, depth, and distance from the edges of the wound are more accurate and apposition of the wound is more secure. Pre-placed sutures have the following further advantages.

(1) They are easier and safer to apply with a firm and steady pressure of the eyeball, and the depth can be controlled more accurately.

(2) The meridian of the pre-placed stitches is more accurate. It is sometimes difficult to apply post-placed stitches in cases with contracted fornices because the edges of the wound are liable to be displaced.

(3) The interval between the section and the completion of the extraction is shorter, and the pupil is less likely to contract.

(4) Any sudden rise in intra-ocular pressure after section is better controlled, as one can close the incision immediately, and expulsive haemorrhage may be avoided.

(5) The risks entailed by through and through stitches are eliminated.

However, this method is not without some drawbacks. There may be difficulty in completing the section after the sutures have been passed through the gutter as the stitches may be cut in the process; this complication can be overcome with practice, and a cut stitch can be replaced by another passed through the same track.

\section{Summary}

The complications of shallow anterior chamber, hyphaema, and iris prolapse which may be associated with suturing and wound-healing in cataract surgery have been assessed in 355 cases in which post-placed corneo-scleral stitches were used and in 313 cases in which sutures were pre-placed. In the latter group the complications were reduced by about 40 per cent. Pre-placed gutter stitches are therefore to be preferred to post-placed stitches.

I am grateful to Dr. Prem Chandra, Professor of Ophthalmology, for his guidance and help. 


\section{REFERENCES}

Arruga, H. (1952). "Ocular Surgery”, trans. from 3rd Spanish ed. by M. J. Hogan and E. E. Chaparro. Salvat, Barcelona.

Bodian, M. (1961). Amer. J. Ophthal., 51, 1243.

Davis, F. A. (1944). Arch. Ophthal. (Chicago), 31, 321.

Dunnington, J. H., and ReGan, E. F. (1953). Ibid., 50, 545.

ESCAPINI, H. (1958). Ibid., 59, 653.

Gómez MÁrquez (1913). "Medicina y Cirurgia” (quoted by Arruga, 1952, p. 486).

Hughes, W. F. (1956). Quoted in "Surgery of the Eye Diseases", by A. Callahan, p. 189. Thomas, Springfield, Ill.

Hughes, W. L., Guy, L. P., and Romaine, H. H. (1944). Arch. Ophthal. (Chicago), $32,362$.

Kalt, E. (1894). Arch. Ophtal., 14, 639.

KifFNeY, G. T., and Stocker, F. W. (1960). Amer. J. Ophthal., 49, 711.

Lemoine, A. N. (1953). Amer. Acad. Ophthal. Otolaryng, Instructional section, p. 275.

LiÉGARD, H. (1913). Ann. Oculist. (Paris), 149, 119.

McLean, J. M. (1940). Arch. Ophthal. (Chicago), 23, 554.

MoOre, J. Gibson (1958). Brit. J. Ophthal., 42, 723.

Roberts, W. (1952). Amer. J. Ophthal., 35, 1459.

Stallard, H. B. (1950). "Eye Surgery", 2nd ed., p. 408-409. Simpkin Marshall, London.

Suarez de Mendoza, F. (1891). Bull. Soc. franç. Ophtal., 9, 64.

VerhoEfF, F. H. (1927). Trans. Amer. ophthal. Soc., 25, 54.

Zorab, E. C. (1961). Brit. J. Ophthal., 45, 614. 